\title{
Correction: Liang et al., Cdk5 Regulates Activity-Dependent Gene Expression and Dendrite Development
}

In the article "Cdk5 Regulates Activity-Dependent Gene Expression and Dendrite Development" by Zhuoyi Liang, Tao Ye, Xiaopu Zhou, Kwok-On Lai, Amy K.Y. Fu, and Nancy Y. Ip, which appeared on pages 15127-15134 of the November 11, 2015 issue, the authors regret an error in Figure 4, $B$ and $C$, where the headings were accidentally reversed during revision. The data and quantification were rechecked and the error was found only in the headings of the two panels. The corrected Figure 4 is shown below.

A
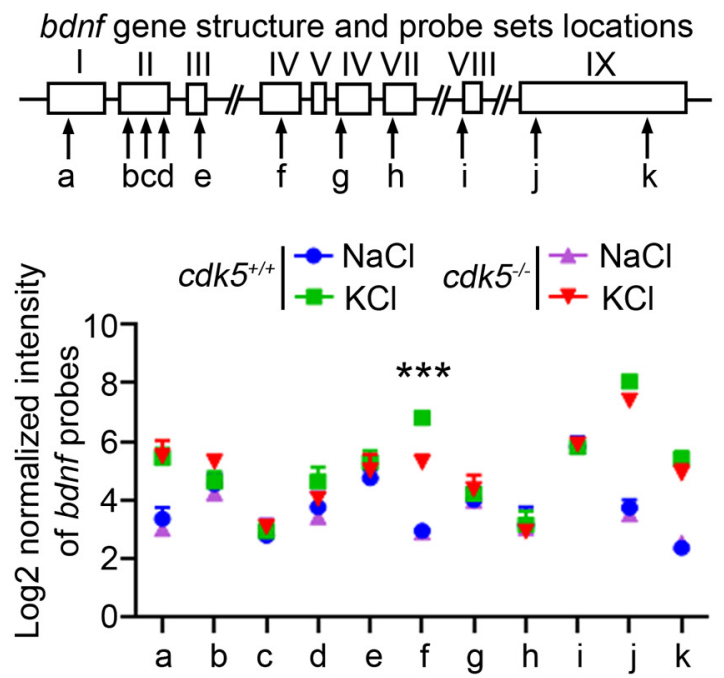

$\mathbf{E}$
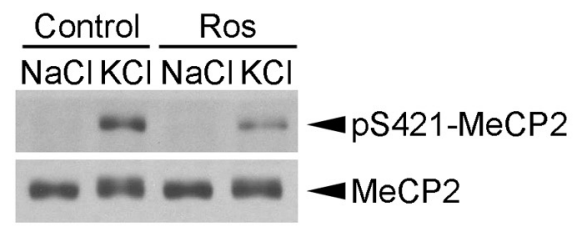

$\mathbf{F}$

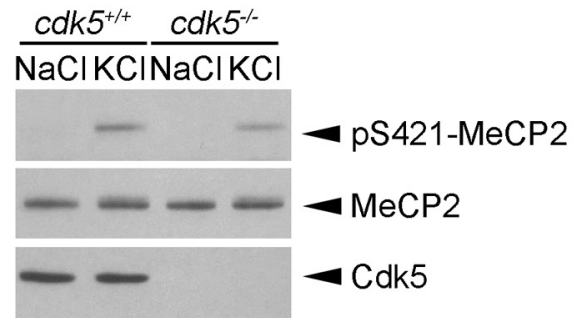

B

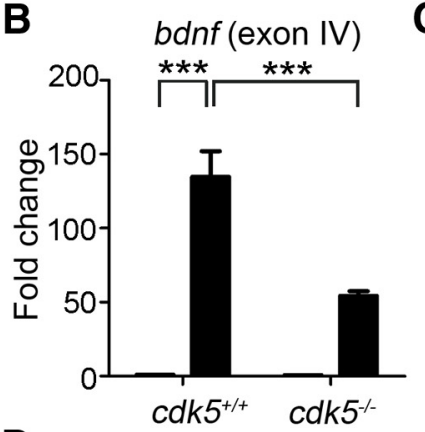

C $\quad b d n f$ (all transcripts)

D

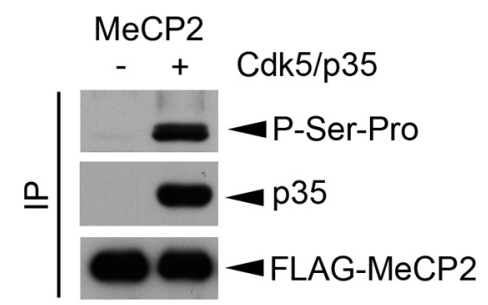

G

MeCP2-associated bdnf (exon IV)

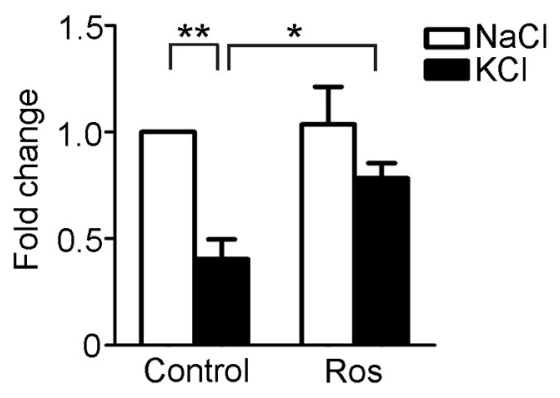

Figure 4. 